\title{
Perancangan Alat Pemotong Label untuk Meminimasi Gerakan Repetitive Pekerja di Industri Jago Jaya Shuttlecock Surakarta
}

\author{
Sherlinta Immanuella Kaban ${ }^{1 *}$, Rahmaniyah Dwi Astuti², Eko Pujiyanto ${ }^{3}$ \\ Program Studi Teknik Industri, Fakultas Teknik, Universitas Sebelas Maret \\ Jalan Ir. Sutami no. 36A, Surakarta, Jawa Tengah, Indonesia \\ sherlintakaban@gmail.com ${ }^{1 *}$, niyah22@gmail.com ${ }^{2}$,ekop2003@ yahoo.com ${ }^{3}$
}

\section{INFO ARTIKEL}

Jejak Artikel :

Upload artikel

22 Juni 2020

Revisi

27 September 2021

Publish

30 September 2021

\section{Kata Kunci :}

Gerakan Repetitif, Perhitungan

Waktu Baku, Assessment of

Repetitive Tasks (ART) Tool,

Peta Tangan Kiri dan Tangan

Kanan, NIDA (Need, Idea,

Decision, and Action)
ABSTRAK

Industri Jago Jaya Shuttlecock merupakan salah satu industri shuttlecock di Surakarta. Proses produksi shuttlecock di industri ini masih menggunakan alat tradisional. Salah satu proses dari keseluruhan proses produksi mengandung beberapa gerakan repetitif yaitu pada proses pemotongan label. Selain itu, tingginya jumlah gerakan repetitif menyebabkan tingginya waktu proses pemotongan. Dikarenakan hal tersebut maka diperlukan adanya perancangan alat pemotong label yang bertujuan untuk mengurangi lamanya proses pemotongan dan gerakan repetitif yang dihasilkan. Penelitian ini menggunakan perhitungan waktu baku untuk menghitung waktu yang diperlukan pada proses pemotongan menggunakan alat saat ini, penilaian Assessment of Repetitive Tasks Tool untuk menilai faktor risiko yang menjadi fokus kebutuhan perancangan alat, serta analisis gerakan menggunakan peta tangan kiri dan tangan kanan. Berdasarkan penilaian Assessment of Repetitive Tasks Tool, faktor risiko pengulangan, pergerakan lengan, serta kecepatan kerja menunjukkan pada level risiko medium. Sedangkan faktor risiko tekanan, postur lengan, dan postur genggaman tangan menunjukkan pada level risiko tinggi. Peta tangan kiri dan tangan kanan menunjukkan adanya beberapa gerakan yang tidak efektif dan berulang pada proses pemotongan label. Perancangan alat pemotong label menggunakan metode NIDA (Need, Idea, Decision, and Action) menghasilkan alat pemotong label yang dapat memenuhi kebutuhan pada proses pemotongan label di Industri Jago Jaya Shuttlecock. 


\section{Pendahuluan}

Bulu tangkis merupakan salah satu cabang olahraga yang sangat popular dan digemari oleh masyarakat Indonesia. Bulu tangkis adalah permainan yang menggunakan raket sebagai alat memukul shuttlecock sebagai objeknya. Tujuan permainan ini adalah menjatuhkan shuttlecock di daerah lapangan lawan dengan melewati atas net untuk mendapatkan poin. Tidak hanya di Indonesia, bulutangkis juga merupakan cabang olahraga yang bergengsi dikalangan dunia. Oleh karena itu, dalam acara pesta besar olah raga se dunia yaitu Indonesia Open 2020 yang dilaksanakan di Indonesia yang mana bulutangkis sebagai cabang olahraga yang ditandingkan. Menjelang Indonesia Open 2020, permintaan shuttlecock di Kota Surakarta mencapai 2000 slop dimana hal ini industri shuttlecock mengalami kenaikan hingga 100\%. Pada tahun sebelumnya data permintaan ratarata 1000 slop dimana setiap slop berisi 12 shuttlecock. Di Jawa Tengah terdapat beberapa industri shuttlecock di setiap wilayahnya. Salah satu industri shuttlecock di Surakarta yang terletak di Jagalan yaitu Industri Jago Jaya Shuttlecock[1].

Industri Jago Jaya Shuttlecock merupakan salah satu Usaha Mikro Kecil Menengah (UMKM) berbasis home industry yang sudah berdiri sejak tahun 1971. UMKM ini berlokasi di RT 05 RW 05 Jagalan, Jebres, Surakarta. Keberadaan Industri Jago Jaya Shuttlecock membuka lapangan pekerjaan bagi masyarakat sekitar. Saat ini terdapat 15 karyawan dengan rentang usia 20-40 tahun. Metode produksi UMKM ini masih tergolong sederhana karena kegiatan produksi disana masih menggunakan sistem tradisional. Target produksi harian dari Industri Jago Jaya Shuttlecock yaitu sekitar 1000 shuttlecock.

Jenis shuttlecock yang diproduksi di Jago Jaya Shuttlecock ini yaitu berdasarkan grade yaitu kualitas premium dan biasa. Untuk membedakan shuttlecock, Industri Jago Jaya Shuttlecock melakukan pemasangan label merk yang ditempel di belakang dop. Label tersebut biasanya berbentuk lingkaran karena mengikuti bentuk dari dop. Industri Jago Jaya Shuttlecock menggunakan label yang dipotong secara manual dengan pisau berbentuk lingkaran dan dipukul menggunakan kayu dan ditempel menggunakan lem. Metode tersebut menggunakan lebih dari satu alat sehingga menggunakan tenaga yang cukup besar dan memerlukan konsentrasi yang tinggi agar menghasilkan potongan stiker yang sempurna.

\section{Metode Penelitian}

Penelitian ini dilakukan pada proses pemotongan label di Industri Jago Jaya Shuttlecock Jagalan. Metode yang digunakan dalam penelitian ini adalah sebagai berikut: kamera smartphone untuk merekam proses pemotongan label, Perhitungan Waktu Baku menggunakan Stopwatch Time Study untuk menentukan waktu standar yang diperlukan dalam proses pemotongan label, Peta Kerja: Peta Tangan Kiri dan Tangan Kanan untuk menggambarkan proses pekerjaan yang dilakukan oleh tangan kiri dan tangan kanan pekerja secara rinci dalam melakukan proses pemotongan label, Assessment of Repetitive Tasks Tool untuk menilai risiko dari anggota tubuh bagian atas yang diakibatkan oleh gerakan repetitif serta memperoleh informasi bagian yang mempunyai level risiko tinggi yang digunakan untuk menentukan kebutuhan rancangan alat, Wawancara dengan pemilik dan pekerja di Industri Jago Jaya Shuttlecock untuk menentukan kebutuhan rancangan alat, metode NIDA (Need, Idea, Decision, dan Action) sebagai metode perancangan alat, dan software Autodesk Fusion untuk merancang desain alat pemotong label[2][3][4][5]. Objek dari penelitian ini yaitu aktivitas pada proses pemotongan label di Industri Jago Jaya Shuttlecock. Sedangkan responden dari penelitian ini yaitu pemilik dan pekerja di Industri Jago Jaya Shuttlecock. Diagram alir penelitian ditunjukkan pada Gambar. 1 sebagai berikut: 


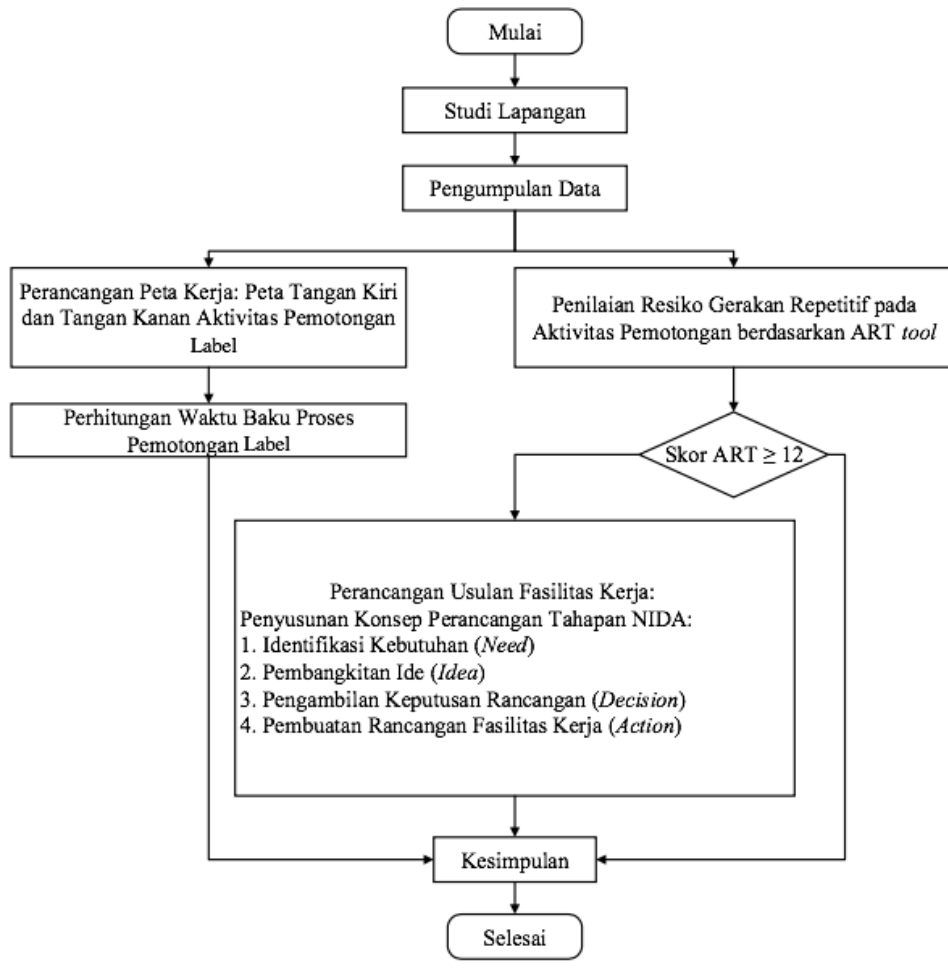

Gambar 1. Diagram Alir Penelitian

\section{Hasil dan Pembahasan}

A. Pengumpulan Data

Pengumpulan data yang dilakukan yaitu berupa waktu proses pemotongan label di Industri Jago Jaya Shuttlecock yang ditunjukkan pada Tabel 1 berikut:

Tabel 1. Waktu Proses Pemotongan

\begin{tabular}{|c|c|c|c|}
\hline $\begin{array}{c}\text { Pengamatan } \\
\text { Ke- }\end{array}$ & $\begin{array}{c}\text { Waktu } \\
(\mathbf{s})\end{array}$ & $\begin{array}{c}\text { Pengamatan } \\
\text { Ke- }\end{array}$ & $\begin{array}{c}\text { Waktu } \\
(\mathbf{s})\end{array}$ \\
\hline 1 & 76 & 11 & 75 \\
\hline 2 & 75 & 12 & 77 \\
\hline 3 & 73 & 13 & 76 \\
\hline 4 & 80 & 14 & 76 \\
\hline 5 & 77 & 15 & 77 \\
\hline 6 & 76 & 16 & 75 \\
\hline 7 & 79 & 17 & 72 \\
\hline 8 & 81 & 18 & 71 \\
\hline 9 & 74 & 19 & 72 \\
\hline 10 & 70 & 20 & 78 \\
\hline
\end{tabular}

Data waktu proses pemotongan labelsejumlah 20 data dibagi menjadi 10 subgroup.
Setelah pengumpulan data waktu proses pemotongan label, lalu dilakukan uji keseragaman dan uji kecukupan data. Berikut adalah perhitungan uji keseragaman dan uji kecukupan data.

\section{A. Uji Keseragaman Data}

Uji keseragaman data dilakukan untuk mengetahui apakah data yang diperoleh sudah seragam, yang ditandai dengan tidak adanya data keluar dari batasan (out of control) [6][7][8]. Gambar. 2 menunjukkan grafik hasil uji keseragaman data.

\section{Uji Keseragaman Data}

80.00

75.00

70.00

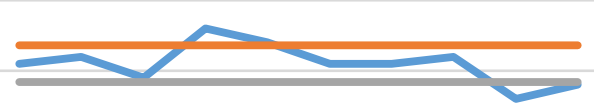

$$
\begin{array}{llllllllll}
1 & 2 & 3 & 4 & 5 & 6 & 7 & 8 & 9 & 10 \\
& & & & & & & & &
\end{array}
$$

Gambar 2. Grafik Uji Keseragaman Data

Berdasarkan uji keseragaman data, data pengamatan yang telah diambil telah seragam.

B. Uji Kecukupan Data

Uji kecukupan data dilakukan untuk menguji apakah data pengataman telah mencukupi atau tidak.

$N^{\prime}=\left[\frac{40 \sqrt{N \sum X_{j}{ }^{2}-\left(\sum X_{j}\right)^{2}}}{\sum X_{j}}\right]$

$N^{\prime}=1,50$

Nilai dari N > N', maka data pengamatan yang diperoleh telah mencukupi.

C. Perhitungan Waktu Baku

Perhitungan waktu baku dilakukan untuk menentukan waktu standar dalam proses pemotongan 1 loyang label. Berikut adalah perhitungan waktu baku dari proses pemotongan label[9][10][11][12].

- Waktu Siklus $W s=\frac{\sum X i}{N}$ 
$W s=75,5$ detik

- Waktu Normal

$W n=W s \times p$

Dengan nilai penyesuaian $=1,25$

$W n=94,38$ detik

- Waktu Baku

$$
\begin{aligned}
& W b= \\
& W n x \frac{100 \%}{100 \%-\text { Allowance } \%} . \\
& W b=142,99 \text { detik }
\end{aligned}
$$

Dengan faktor kelonggaran

\begin{tabular}{|c|c|c|}
\hline No & Faktor & Kelonggaran \\
\hline 1 & Tenaga yang dikeluarkan & $6 \%$ \\
\hline 2 & Sikap kerja & $0 \%$ \\
\hline 3 & Gerakan kerja & $5 \%$ \\
\hline 4 & Kelelahan mata & $6 \%$ \\
\hline 5 & Keadaan suhu tempat kerja & $10 \%$ \\
\hline 6 & Keadaan atmosfer & $5 \%$ \\
\hline 7 & Keadaan lingkungan yang baik & $2 \%$ \\
\hline & Total & $34 \%$ \\
\hline
\end{tabular}
dijabarkan pada Tabel 2 berikut:

Tabel 2. Faktor Kelonggaran

Pada tenaga yang dikeluarkan termasuk dalam kategori sangat ringan, sikap kerja dengan duduk, gerakan kerja yang sulit, kelelahan mata termasuk dalam kategori pandangan yang terputus-putus, keadaan suhu tempat kerja yang tinggi, keadaan atmosfer yang cukup bising, serta siklus kerja yang berulang antara 0-5 detik.

\section{Peta Tangan Kiri dan Tangan Kanan}

Peta tangan kiri dan tangan kanan dilakukan untuk menunjukkan gerakan yang dilakukan oleh tangan kiri dan tangan kanan secara detail[13][14][15]. Peta tersebut ditunjukkan pada Tabel 3 di bawah ini:
Tabel 3. Peta Tangan Kanan Tangan Kiri

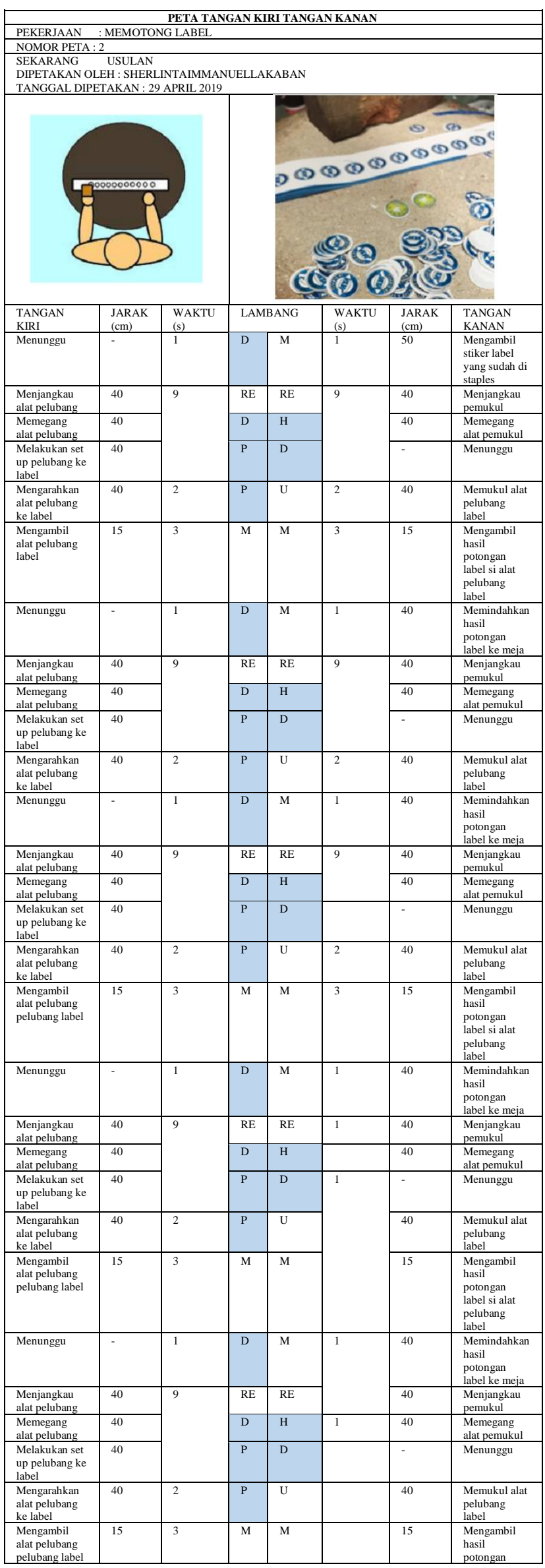


MATRIK : Jurnal Manajemen \& Teknik Industri - Produksi Volume XXII, No.1, September 2021, Halaman 65 - 72

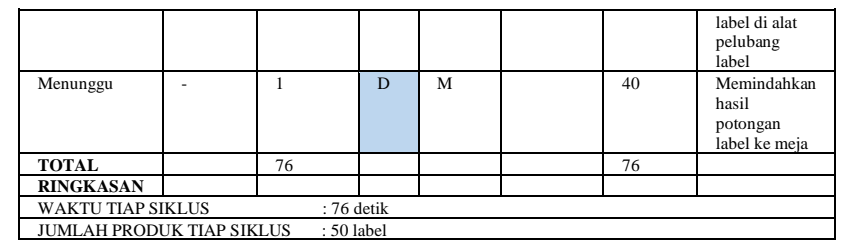

Pada peta tangan kiri dan tangan kanan di atas, lambang D menunjukkan delay, lambang RE menunjukkan reach, lambang G menunjukkan grasp, lambang $\mathrm{M}$ menunjukkan move, lambang $\mathrm{H}$ menunjukkan hold, lambang $\mathrm{P}$ menunjukkan position, lambang $\mathrm{U}$ menunjukkan use, dan lambang RL menunjukkan release.

Berdasarkan peta tangan kiri dan tangan kanan, proses pemotongan label menggunakan alat yang digunakan saat ini menghasilkan gerakan repetitif dan gerakan yang tidak efektif pada kedua tangan. Gerakan yang tidak efektif tersebut meliputi position sebanyak 10 kali, delay sebanyak 16 kali, dan hold sebanyak 5 kali. Selain itu, jarak yang dilakukan oleh tangan kiri dan tangan kanan tidak seimbang.

D. Assessment of Repetitive Tasks Tool

Assessment of Repetitive Tasks Tool (ART Tool) bertujuan untuk menilai risiko pada anggota tubuh bagian atas (tangan dan lengan) yang ditimbulkan dari gerakan repetitif. Gambar. 3 menunjukkan form penilaian Assessment of Repetitive Tasks Tool.

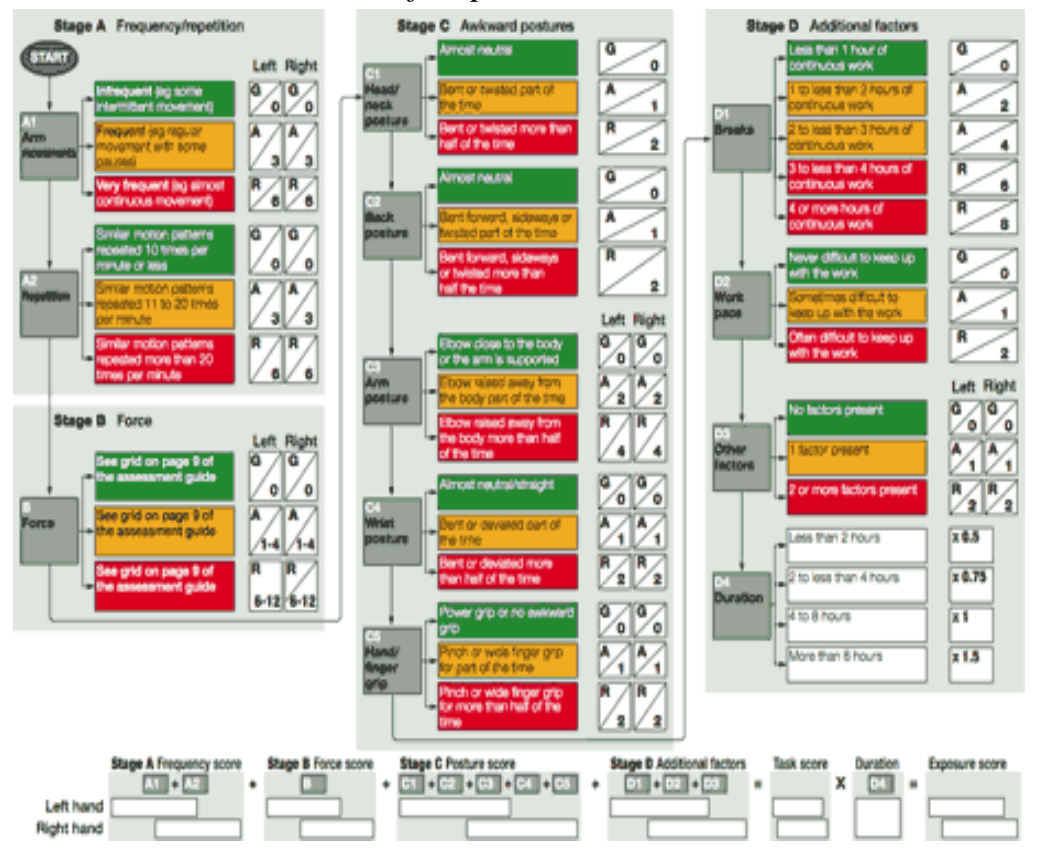

Gambar 3. Form Penilaian Assessment of Repetitive Tasks Tool
p-ISSN: $1693-5128$, e-ISSN : 2621-8933

doi: 10.350587/Matrik v22i1.1527

Form tersebut digunakan untuk menilai risiko dari tangan kiri dan tangan kanan pada postur proses pemotongan label. Gambar. 4 menunjukkan gambar postur kerja dari proses pemotongan label untuk dinilai menggunakan ART Tool.

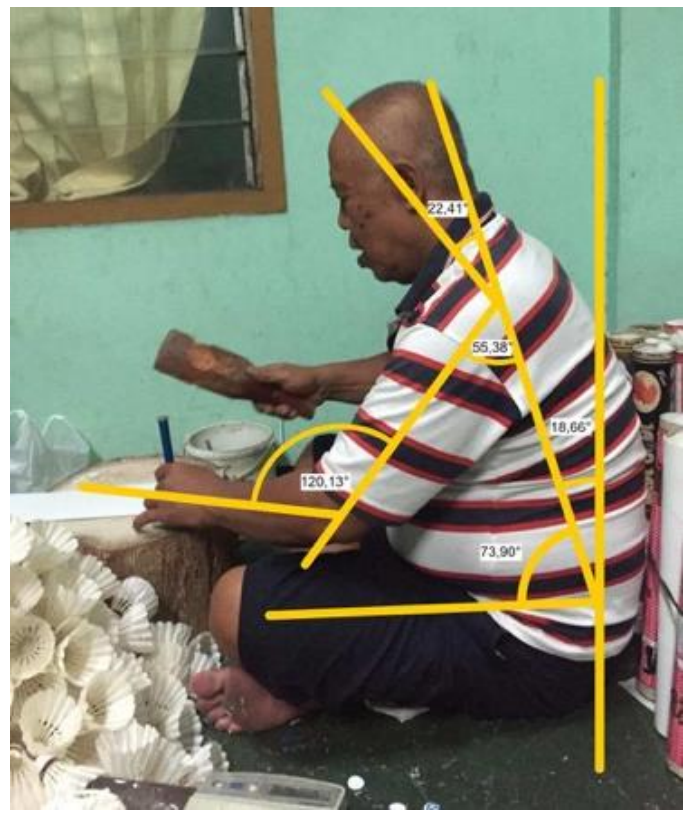

Gambar 4. Postur Kerja Proses Pemotongan Label

Postur kerja tersebut kemudian dianalisis menggunakan Assessment of Repetitive Tasks Tool. Pada Tabel 4 menunjukkan hasil penilaian risiko penilaian berdasarkan Assessment of Repetitive Tasks Tool.

Tabel 4. Hasil Penilaian Risiko

\begin{tabular}{|l|l|c|c|c|c|}
\hline \multicolumn{9}{|c|}{ Lembar Penilaian } \\
\hline \multicolumn{2}{|c|}{ Faktor Resiko } & \multicolumn{2}{c|}{ Tangan Kiri } & \multicolumn{2}{c|}{ Tangan Kanan } \\
\hline A1 & Pergerakan lengan & & A3 & & A3 \\
\hline A2 & Pengulangan & & A6 & & A6 \\
\hline B & Tekanan & & R8 & & R8 \\
\hline C1 & $\begin{array}{l}\text { Postur } \\
\text { Kepala/Leher }\end{array}$ & & G0 & & G0 \\
\hline C2 & Postur Punggung & & G0 & & G0 \\
\hline C3 & Postur Lengan & & R4 & & R4 \\
\hline C4 & $\begin{array}{l}\text { Postur } \\
\text { Pergelangan }\end{array}$ & & G0 & & G0 \\
\hline C5 & $\begin{array}{l}\text { Postur Genggaman } \\
\text { Tangan }\end{array}$ & & R2 & & G0 \\
\hline D1 & Istirahat & G0 & & G0 \\
\hline D2 & Kecepatan Kerja & A0 & & A1 \\
\hline D3 & Faktor Lain Skor Aktivitas & G0 & & G0 \\
\hline \multicolumn{2}{|c|}{ Exposure Score } & X 0,5 & & X 0,5 \\
\hline D4 & Pengali Durasi & & $\mathbf{1 1}$ \\
\hline \multicolumn{2}{|l|}{} & & \\
\hline
\end{tabular}

Nilai akhir yang diperoleh dari penilaian tersebut lalu diinterpretasikan berdasarkan Gambar. 5 di bawah ini: 


\begin{tabular}{|l|l|l|}
\hline Exposure score & Proposed exposure level \\
\hline $0-11$ & Low & $\begin{array}{l}\text { Consider Individual } \\
\text { ciecumstances }\end{array}$ \\
\hline $12-21$ & Medium & $\begin{array}{l}\text { Further } \\
\text { investigation } \\
\text { required }\end{array}$ \\
\hline 22 or more & High & $\begin{array}{l}\text { Further } \\
\text { investigation } \\
\text { required urgently }\end{array}$ \\
\hline
\end{tabular}

Gambar 5. Nilai Akhir

Berdasarkan interpretasi nilai akhir, maka proses pemotongan label dengan alat yang saat ini digunakan menghasilkan level risiko medium pada kedua tangan.

\section{E. Perancangan Alat Pemotong Label: \\ Metode NIDA}

Metode NIDA meliputi 4 tahap, yaitu perancangan kebutuhan, pembangkitan ide, penentuan desain alternatif, dan pembuatan alat.

1) Tahap 1: NEED

Pada tahap ini perancang menentukan kebutuhan dari rancangan alat. Kebutuhan tersebut diperoleh dari wawancara dengan pemilik dan pekerja di Industri Jago Jaya Shuttlecock dan faktor risiko dengan level medium dan tinggi berdasarkan penilaian ART Tool. Tabel 5 menunjukkan hasil kebutuhan dari rancangan..

Tabel 5 . Hasil kebutuhan dari rancangan.

\begin{tabular}{|c|c|c|c|}
\hline \multirow[b]{2}{*}{ Hasil Wawancara } & \multicolumn{2}{|c|}{ Penilaian ART Tool } & \multirow[b]{2}{*}{$\begin{array}{l}\text { Simbol } \\
\text { Warna }\end{array}$} \\
\hline & Tangan Kiri & Tangan Kanan & \\
\hline $\begin{array}{l}\text { Waktu proses } \\
\text { pemotongan label } \\
\text { yang lama } \\
\text { dikarenakan alat } \\
\text { yang digunaka } \\
\text { masih tradisional } \\
\text { serta penggunaan } \\
\text { secara manual dan } \\
\text { menyebabkan } \\
\text { adanya ovetime, } \\
\text { terutama saat } \\
\text { permintaan sedang } \\
\text { tinggi }\end{array}$ & $\begin{array}{l}\text { Pergerakan } \\
\text { Lengan }\end{array}$ & $\begin{array}{l}\text { Pergerakan } \\
\text { Lengan }\end{array}$ & \\
\hline $\begin{array}{l}\text { Ukuran hasil } \\
\text { pemotongan label } \\
\text { yang tidak sesuai } \\
\text { dengan ukuran } \\
\text { sehingga tidak } \\
\text { bisa digunakan } \\
\text { pada shuttlecock }\end{array}$ & $\begin{array}{l}\text { - Pengulangan } \\
\text { - Tekanan } \\
\text { - Postur } \\
\text { Lengan } \\
\text { - Postur } \\
\text { Genggaman } \\
\text { Tangan }\end{array}$ & $\begin{array}{l}\text { - Pengulangan } \\
\text { - Tekanan } \\
\text { - Postur } \\
\text { Lengan }\end{array}$ & \\
\hline
\end{tabular}

2) Tahap 2: IDEA

Pada tahap ini perancang mengembangkan ide yang didapatkan dari kebutuhan yang telah ditentukan. Ide dari rancangan alat ini didapatkan dari kebutuhan serta penelitian terdahulu mengenai perancangan alat pemotong label.

Tabel 6. Hasil Ide Yang Dikembangkan.

\begin{tabular}{|c|c|c|}
\hline No. & Kebutuhan & Fitur Alat \\
\hline 1. & $\begin{array}{l}\text { Alat pemotong label yang apabila } \\
\text { digunakan tidak menimbulkan rasa } \\
\text { sakit di bagian punggung. }\end{array}$ & $\begin{array}{l}\text { Alat pemotong label dilengkapi dengan } \\
\text { handle yang terletak tidak menjauhi dari } \\
\text { tubuh maka dapat meminimalkan } \\
\text { postur membungkuk. }\end{array}$ \\
\hline 2. & $\begin{array}{l}\text { Alat pemotong label yang apabila } \\
\text { digunakan dapat meminimalkan waktu } \\
\text { proses pemotongan. }\end{array}$ & $\begin{array}{l}\text { Alat pemotong label didesain dengan } \\
\text { menyusun dengan menggabungkan } \\
\text { fungsialat pemukuldan pelubang } \\
\text { dengan jumlah dan ukuran yang } \\
\text { disesuaikan dengan ukuran label } \\
\text { sehingga dapat memotong label dalam } 1 \\
\text { kali proses dan adanya minimalisasi } \\
\text { waktu proses pemotongan label. }\end{array}$ \\
\hline 3. & $\begin{array}{l}\text { Alat pemotong labek yang dapat } \\
\text { menghasilkan potongan label dengan } \\
\text { ukuran yang diharapkan sehingga tidak } \\
\text { menghasilkan label yang tidak bisa } \\
\text { digunakan. }\end{array}$ & $\begin{array}{l}\text { Terdapat pisau pemotong yang memiliki } \\
\text { ukuran yang sesuai dengan label } \\
\text { sehingga dapat memotong secara presisi. }\end{array}$ \\
\hline 4. & $\begin{array}{l}\text { Alat pemotong label yang dapat } \\
\text { mengurangi atau menghilangkan } \\
\text { jumlah gerakan berulang pada tangan } \\
\text { kiri dan tangan kanan. }\end{array}$ & $\begin{array}{l}\text { Alat pemotong label didesain dengan } \\
\text { menggabungkan alat pelubang dan } \\
\text { pamukul sehingga mempersingkat } \\
\text { gerakan menjadi } 1 \text { kali gerakan yang } \\
\text { dilakukan oleh tangan kiri dan tangan } \\
\text { kanan secara bersamaan. }\end{array}$ \\
\hline 5. & $\begin{array}{l}\text { Alat pemotong label yang dapat } \\
\text { mengurangi frekuensi dari pergerakan } \\
\text { lengan kanan dan lengan kiri. }\end{array}$ & $\begin{array}{l}\text { Alat pemotong label didesain sederhana } \\
\text { dan lebih praktis sehingga mudah } \\
\text { digunakan oleh semua operator dengan } \\
\text { waktu yang singkat dan hasil }\end{array}$ \\
\hline 6. & $\begin{array}{l}\text { Alat pemotong label yang mudah } \\
\text { digunakan untuk semua operator(tidak } \\
\text { hanya operator stasiun pemotongan } \\
\text { yang bisa menggunakannya) sehingga } \\
\text { kecepatan pengerjaan sama (tidak } \\
\text { memerlukan keterampilanoperator). }\end{array}$ & pemotongan. \\
\hline 7. & $\begin{array}{l}\text { Alat pemotong label yang dapat } \\
\text { digunakan tanpa memerlukan tekanan } \\
\text { berlebih ("pinching orgripping objects } \\
\text { with some efforts" dan "using } \\
\text { tools with some efforts"). }\end{array}$ & $\begin{array}{l}\text { Alat pemotong label dilengkapi dengan } \\
\text { pisau sehingga tidak perlu tekanan yang } \\
\text { tinggi karna label sudah otomatis } \\
\text { terpotong oleh pisau pemotong label. }\end{array}$ \\
\hline 8. & $\begin{array}{l}\text { Alat pemotong label yang } \\
\text { digunakan, postur lengan } \\
\text { menjauhi badan operator. }\end{array}$ & $\begin{array}{l}\text { Rancangan alat dilengkapi dengan } \\
\text { handle dengan jarak yang tidak } \\
\text { berjauhan dengan badan operator. }\end{array}$ \\
\hline
\end{tabular}

\section{3) Tahap 3: DECISION}

Pada tahap ini perancang memberikan alternatif rancangan alat pemotong label lalu diputuskan rancangan yang terpilih. Keputusan rancangan ditentukan oleh pekerja di Industri Jago Jaya Shuttlecock sebagai operator pemotongan label. 
Tabel 7. Alternatif Desain Alat Pemotong Label.

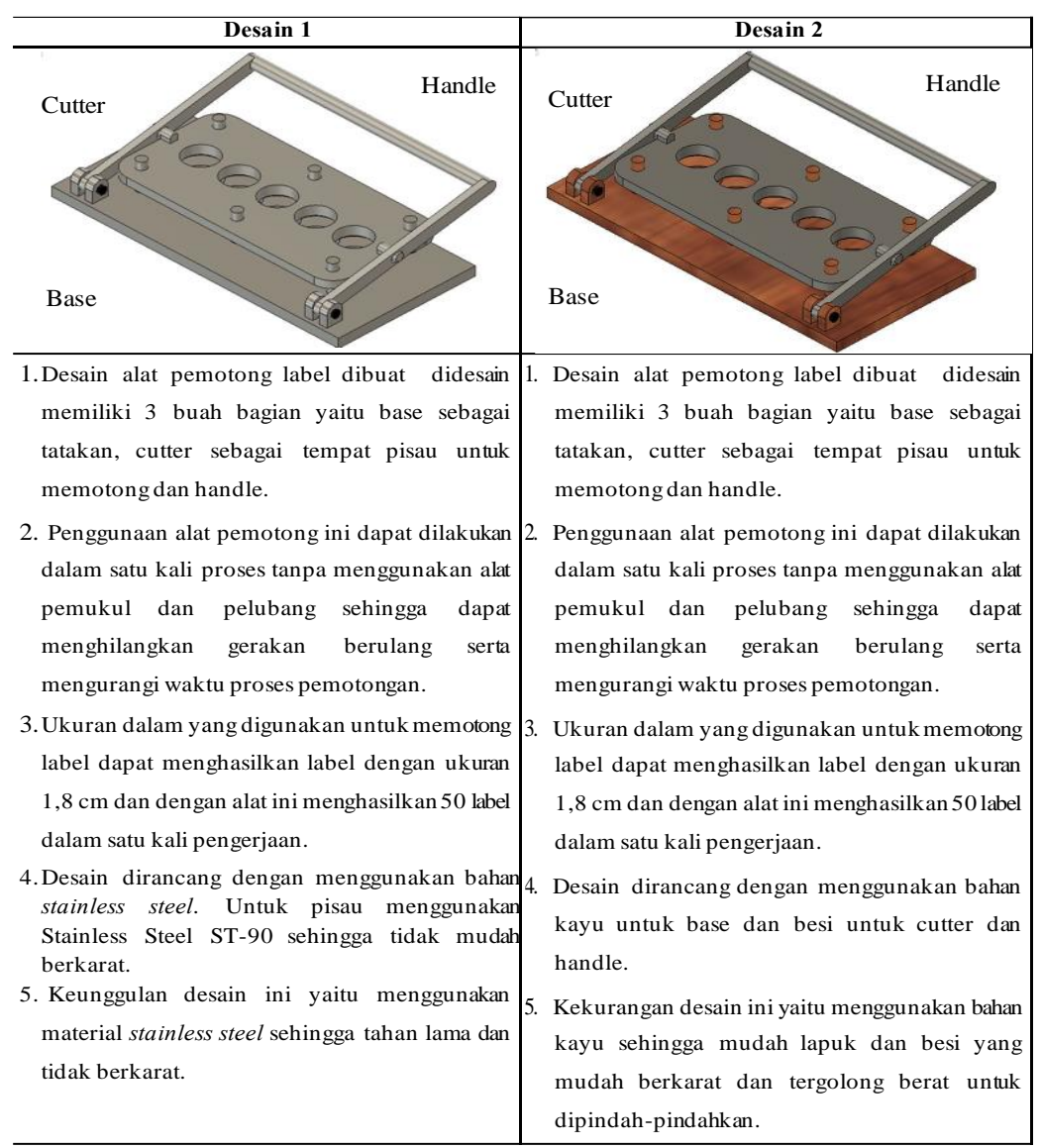

\section{4) Tahap 4: ACTION}

Pada tahap ini perancang menentukan spesifikasi alat pemotong label untuk dilakukan perancangan alat yang terpilih pada tahap sebelumnya.

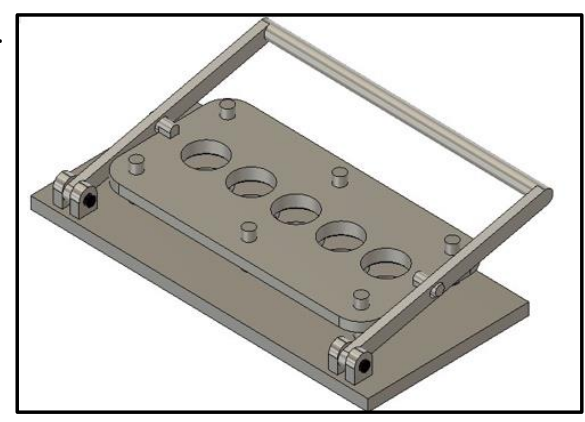

Gambar 6. desain alat pemotong label yang terpilih
Spesifikasi alat pemotong:

1. Berbahan Stainless steel/

2. Terdiri dari tiga bagian yaitu base (berukuran $150 \mathrm{~mm} \times 71,5 \mathrm{~mm} \times 5 \mathrm{~mm}$ ), cutter (berukuran $118 \mathrm{~mm} \times 58,5 \mathrm{~mm}$ x 4 $\mathrm{mm}$ ) dan handle (lebar 120,11 mm)

3. Memiliki 5 pisau pemotong yang terbuat dari pisau stainless steel ST-90.

\section{Kesimpulan dan Saran}

Berdasarkan analisis gerakan menggunakan Assessment of Repetitive Tasks Tool menunjukkan bahwa pekerjaan dengan gerakan berulang menimbulkan risiko pada anggota tubuh bagian atas. Proses pemotongan label dengan alat yang digunakan saat ini, yaitu alat pelubang dan pemukul dari kayu dapat menimbulkan gerakan repetitif yang tinggi serta berisiko pada beberapa bagian tubuh. Faktor risiko yang memiliki level risiko medium yaitu pergerakan lengan. Sedangkan pengulangan, tekanan, postur lengan, postur genggaman tangan menunjukkan pada level risiko tinggi. Peta tangan kiri dan tangan kanan menunjukkan adanya ketidakseimbangan gerakan dan jarak yang dilakukan oleh kedua tangan operator saat melakukan proses pemotongan. Waktu baku yang diperlukan oleh operator dalam melakukan proses pemotongan yaitu 76 detik.

Untuk menurunkan nilai risiko dan waktu proses pemotongan label, maka dilakukan adanya perancangan alat pemotong label shuttlecock. Dengan menggunakan metode NIDA diperoleh rancangan alat pemotong label yang disesuaikan dengan kebutuhan di Industri Jago Jaya Shuttlecock.

\section{Daftar Pustaka}

[1] Muhammad, "Perancangan Permainan Simulasi Bisnis pada Perusahaan Shuttlecock Sebagai Alat Bantu Praktikum Perancangan Teknik Industri,” pp. I-1-VI-1, 2010.

[2] G. K. Dewanti, “Analisis Metode Kerja Perakitan Kipas Angin Pada Proses Servis Kipas Angin Menggunakan Peta Tangan Kiri dan Tangan Kanan," STRING (Satuan Tulisan Ris. dan Inov. Teknol., vol. 5, no. 1, p. 11, 2020, doi: 
10.30998/string.v5i1.5887.

[3] M. Andriani and E. Erfani, "Jisi : Jurnal Integrasi Sistem Industri Volume 4 No 2 Agustus 2017 Perancangan Ulang Egrek Yang Ergonomis Untuk Meningkatkan Produktivitas Pekerja Pada Saat Memanen Sawit," vol. 4, no. 2, pp. 119-128, 2017, doi: 10.24853/jisi.4.1.pp-pp.

[4] Maryana and S. Meutia, "Perbaikan Metode Kerja Pada Bagian Produksi," J. Teknovasi, vol. 02, no. 1, pp. 15-26, 2015, [Online]. Available:

https://media.neliti.com/media/publicati ons/225731-perbaikan-metode-kerjapada-bagian-produ-c6cd423d.pdf.

[5] C. Prilyanto, "Perancangan Alat Bantu Cuci Tangan Dengan Teknologi Sederhana [Pedal Kaki]," Media Apl., vol. 12, no. 1, pp. 13-20, 2020.

[6] R. A. Simanjuntak and D. Hernita, "Usulan Perbaikan Metode Kerja Berdasarkan Micromotion Study Dan Penerapan Metode 5s Untuk Meningkatkan Produktifitas," pp. 191203.

[7] I. Ghazali, D. T. Industri, F. Teknik, U. S. Utara, K. Musculoskeletal, and W. Siklus, "Perancangan Alat Pemeras Kelapa Parut Menjadi Santan," vol. 2, no. 2, pp. 19-27, 2013.

[8] Nofirza and D. Syahputra,

"Perancangan alat pemotong nenas yang ergonomis untuk meningkatkan produktivitas," J. Ilm. Tek. Ind., vol. 11, no. 1, pp. 41-50, 2016.

[9] J. Integrasi and S. Industri,

"Perancangan Fasilitas Kerja yang Ergonomis pada Proses Pelarutan," vol. 3, no. 1, pp. 7-14, 2016.

[10] A. S. Husna, I. W. Kirana, and D. Sari, "Perancangan Meja Ertika ( Ergonomis dan Beretika ) Pada Siswa Taman Kanak-kanak Dengan Metode Quality Function Development," pp. 7-8, 2019.

[11] C. Nathania, I. Iftadi, and R. D. Astuti, "MATRIK Jurnal Manajemen dan Teknik Industri-Produksi Perancangan Bak Penampung Bobin di PT . Iskandar
Indah," vol. XX, no. 2, pp. 91-102, 2020, doi: 10.350587/Matrik.

[12] A. Setiawan, "Perancangan Kursi Operator Cold Shear Dengan Pendekatan Ergonomi Antrophometri Dan Analytical Hierarchy Process Di Pt . Ispat Panca Putera," Matrik, vol. XVIII, no. 1, pp. 1-9, 2017.

[13] R. F. Gumilang and F. Fahma, "Perancangan Peta Tangan Kanan Tangan Kiri Bagian After Market Divisi Packaging PT. XYZ Indonesia," Semin. dan Konf. Nas. IDEC, pp. 433441, 2017.

[14] A. Widodo and R. Astuti, "Perancangan Alat Bantu Untuk Memperbaiki Postur Kerja Aktivitas Memelitur Dalam Proses Finishing," Semin. Nas. IENACO 2015 ISSN 2337-4349, pp. 30-37, 2015.

[15] S. Ramdhani, "Perancangan Alat Pengupas Kulit Lunak Melinjo Yang Ergonomis Dengan Pendekatan Metode Rasional Untuk Meningkatkan Produktivitas Produksi,” 2013. 